\title{
The Influence of Religious and Cosmological Beliefs on the Solar Architecture of the Ancient World
}

\author{
Ezequiel Uson Guardiola ${ }^{1,}$, Joan Lluis Fumado Alsina ${ }^{1}$ and Josep Vives Rego ${ }^{2}$ \\ ${ }^{1}$ Polytechnic University of Catalonia (UPC), Spain \\ ${ }^{2}$ University of Barcelona (UB), Spain
}

\begin{abstract}
In the earliest civilizations of the Ancient World, sun worship developed in parallel with an understanding of the movement of the stars. That was the origin of an architecture that expressed a number of religious and cosmological beliefs. Studies of ancient archaeological remains have revealed that astronomical orientations strongly influenced the construction of some of the most important ancient architectural monuments.

Besides its religious role, the sun regulated the culture of the Ancient World in many of its more practical aspects. For instance, the observation of solar and lunar cycles allowed people to anticipate seasonal change. This provided man with a means of organizing and improving agricultural and livestock activities and, in turn, influenced the construction of the large civil and religious buildings.

The complex relationships that developed between cosmology, sun worship, early mathematics, and the orientation of buildings with respect to the position of the sun, also decisively influenced the birth and development of what has come to be known as passive solar design.

This article describes some of these influences dating from the megalithic period to the development of Mesopotamian and Egyptian architecture.
\end{abstract}

Keywords: Cosmology, sun worship, ancient world, passive solar design.

\section{INTRODUCTION}

Since prehistoric times, man has looked to the skies to discover the mystery behind the movement of the stars. Their apparent trajectories around our planet and their eclipses, solstices and equinoxes constituted an indecipherable secret that acquired a precise religious meaning in different primitive cultures.

The fascination provoked by the Sun, the star that gives us life, is understandable: it is our primary source of energy and life on earth depends on its light and heat. It also determines our climate and seasons, generating day and night and constituting the most direct source of human welfare.

In the Neolithic Period, humans were nomads who had adapted their way of life to the Sun: migrating to warmer areas when the winter season began so that they could continue farming and raising livestock. One of their primary concerns was to understand the solar and lunar cycles so as to be able to predict seasonal changes.

Sun worship can be seen in the religious beliefs of the first urban cultures and in those that continue the Sun worship, even today. In these societies, the Sun is venerated as a god, and constitutes the central

*Address correspondence to this author at the Polytechnic University of Catalonia (UPC), Spain; Tel: +34 934016370; E-mail: ezequiel.uson@upc.edu element of their religious beliefs. The significance of this religious sentiment is reflected in the importance given to the astronomically influenced orientations of their buildings. The need that they felt to keep a record of celestial observations led them to systematize this knowledge and to use it in the creation and spatial organisation of some of the most important cities and monuments in the ancient world.

In the earliest civilizations, and as a consequence of these influences, the construction of monuments was not fortuitous or random; there were buildings whose design, in addition to having religious or military connotations, was influenced by astronomical relations which emphasised the divine nature of the ruling elites. The layouts and structural principles of such constructions do not generally follow merely casual patterns. Instead, they tend to have precise orientations and are based on accurate geometric relations associated with solstices and equinoxes. As a result, the constructions assume the function of astronomical calendars, capable of indicating seasonal change with precision.

\section{REMAINS FROM THE MEGALITHIC PERIOD}

Stonehenge, which is located on Salisbury Plain, in central-southern England, is an impressive megalithic monument which is over 3200 years old and which exemplifies these intentions and provides evidence of the complex astronomical knowledge of its builders. Its 

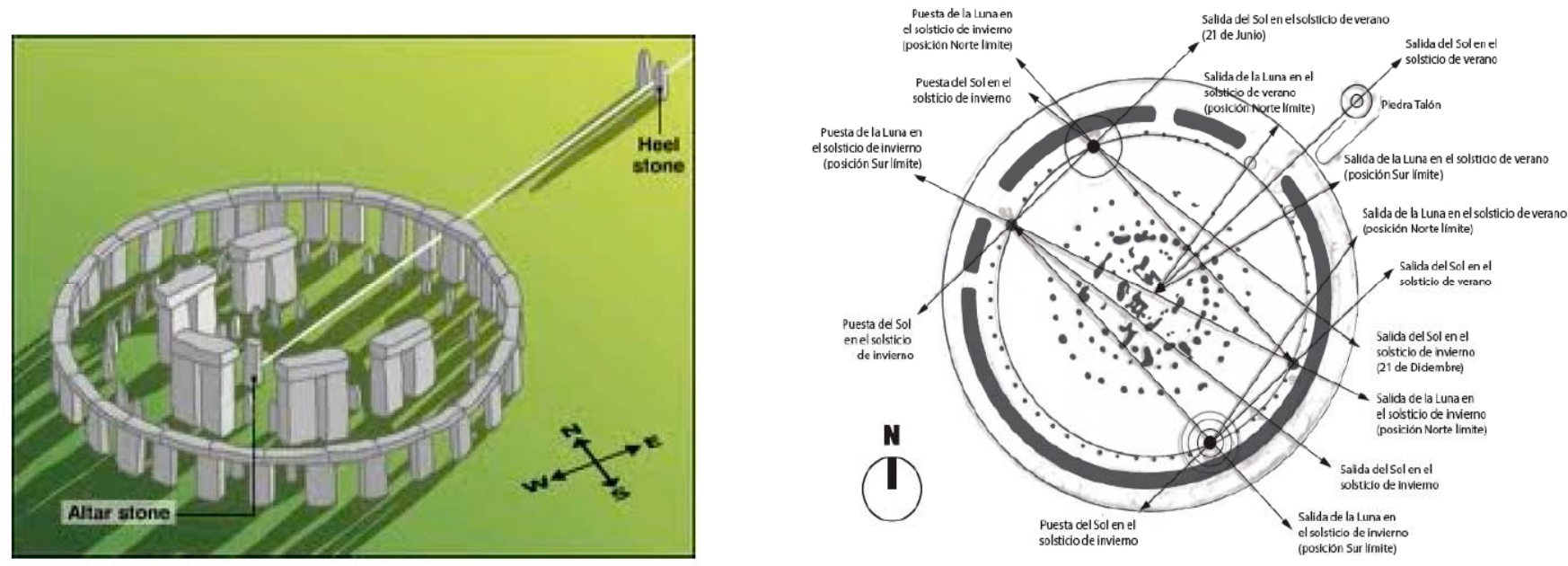

Figure 1: Left: Stonehenge, 3200-1600 B.C, showing its alignment to sunrise at the summer solstice and (right) its sunset alignment at the winter solstice.

exact purpose and origin are still not completely understood, but it is generally assumed to have been a sacred site used for ritual purposes, representing the sublime power of the natural forces. It was also a precise astronomical observatory with which the alignment of the planets and stars could be studied and used to predict celestial and/or seasonal events such as solstices, equinoxes and lunar phases. As such, besides its religious significance, it also served a practical function: it helped its users to anticipate seasonal changes and thereby improve the scheduling of agricultural activities [1].

Archaeological and astronomical investigations indicate that the circle formed by the enormous grey stones, which were transported from a quarry more than 80 kilometres away, is aligned with both the position of the sun at sunrise corresponding to the summer solstice and a sunset corresponding to the winter solstice. Interestingly, the alignment of the southern circle of Durrington Wall, which is another henge located three kilometres to the northwest, corresponds to dawn at the winter solstice ${ }^{1}$ (Figure 1). Stonehenge was used as an astronomical calendar to predict eclipses of the Sun and the moon and was a place at which to worship the twelve Zodiac Gods. Stonehenge is one of the dozens of monuments with astronomical alignments that have been identified to date [2].

${ }^{1}$ In 1901, the astronomer Norman Lockyer noticed that the altar stone and heel stone were aligned with the sunrise at the summer solstice, on June $21^{\text {st }}$, with a margin of error of only 56 minutes of an arch (if the builders of Stonehenge had aligned it with total accuracy at the moment of its construction, this would allow us to date the construction of Stonehenge, as a solar temple, to $1800 \mathrm{BC}$.

\section{COSMOLOGICAL INFLUENCES ON THE MESOPOTAMIAN AND EGYPTIAN CULTURES}

Remains of the Mesopotamian civilization have been found between the rivers Tigris and Euphrates. This was an advanced, agricultural society with a wellstructured political system. Archaeological excavations have revealed the first evidence of stable urban communities in which grain was produced and stored, commercial activities were developed and the leaders and governors were thought to have divine attributes. In this society, observing the stars and ritual orientations were part of daily life. References to sun worship $^{2}$ have also been found in other related civilizations: the Sumerians and Babylonians. The former worshiped the Sun God, Shamash, at the Sippar sanctuary, in what is modern-day Iraq. The Sumerians were also the first astronomers who possessed what is known as a heliocentric vision. [3]

In the Sumerian cities of the Tigris and Euphrates valleys, the close relationship that existed between the divinity and the monarch was manifested through an intense urban landscape dominated staggered towers called Ziggurats. These constructions consisted of a series of long, wide, superimposed platforms, on top of which a temple was built. They were considered to be the dwellings of the gods and had an astronomical function - stellar observation - as well as their symbolic

${ }^{2}$ In primitive Persian civilizations, Mithra was the Sun God. The Romans also accepted this god in their mythology, as a divinity to which they gave the title "God of the Undefeated Sun". In India, a wheel, or a golden plate, represented the Sun. At dawn, the Sun was received with a silent dance, which sought to imitate the Sun's orbital movement. In primitive Scandinavian villages, a great solar disc was worshiped; this is known from drawings found on rocks that date from the Bronze Age. 


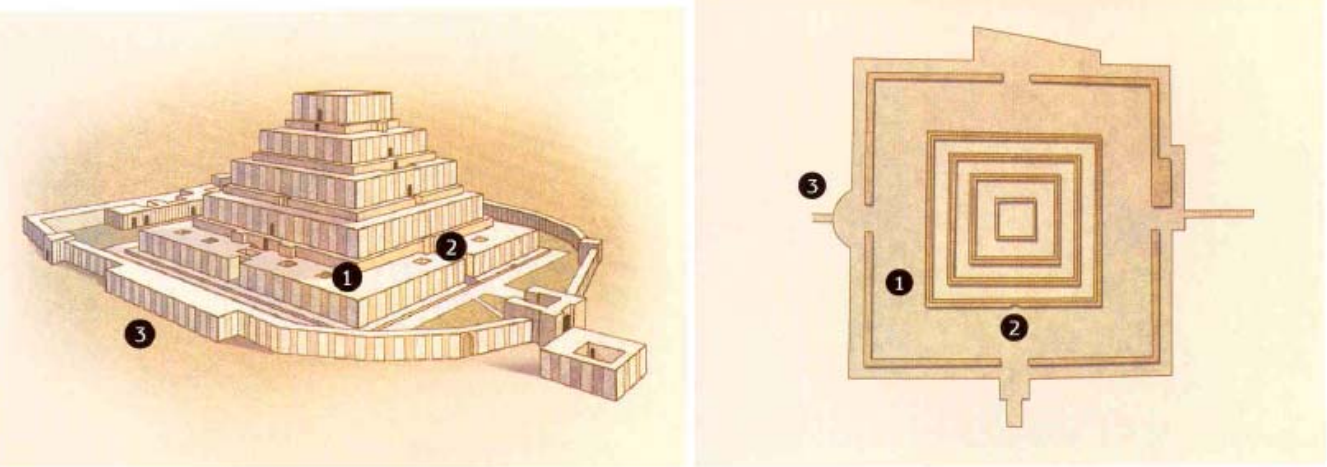

Figure 2: Ceremonial centres: Chogha Zanbil, or Dur Untash, the ziggurat built by king Untash-Napirisha, $13^{\text {th }}$ century BC: $(1) \mathrm{A}$ large square building with 100 metre-long Sides; (2) Four monumental stars providing access to the temple located at the top; (3) The perimeter wall of the ziggurat (Source: National Geographic).

significance: according to some authors, the Sumerians conceived them as cosmic axes that provided a vertical connection between the earth and the heavens (Figure 2).

Passive solar design originated from this civilization and as consequence of these complex relations and of the application of astronomical knowledge in daily life. The courtyard housing provides an example of the regulation of solar radiation through observation of the position of the Sun and a precise knowledge of its elliptical orbit from sunrise to sunset during different seasons.

Courtyard housing is an example of the application of these strategies in one of the most ancient domestic construction typologies; there are remains of this typology dating back 5,000 years. It originally developed as an answer to the need to find a means of protecting settlements from external dangers such as attacks from other humans or from wild animals, but it subsequently evolved into a solid, logical configuration which was well-adapted to the hot, arid climate. The climatic advantages of the courtyard are clearly evident: it provides a protected outdoor area which permits the incorporation of ingenious strategies of natural ventilation. It gives protection against winds carrying dust or sand, and at the same time reduces the impact of excessive solar radiation.

This typology was also well adapted to the context of these first urban settlements, which grew up without planned layouts of any kind. The climatic and functional efficiency of courtyard housing make this the most appropriate typology for shaping a residential urban fabric, with low height and high density housing units which maximize the constructed area [4]. This type of housing has been very well documented from remains found in archaeological excavations of settlements belonging to the Sumerian culture. Good examples were found in the excavations conducted by Woolley, in 1926-27, at the former port city of Ur (Hisham, 2003). This settlement was founded in $2560 \mathrm{BC}$, a period corresponding to the hegemony of Lower Mesopotamia (Figures 3 and $\mathbf{4}$ ).

\section{THE NILE VALLEY CULTURE}

In no other place can we observe natural geography more related to solar orientation than in the Nile Valley.

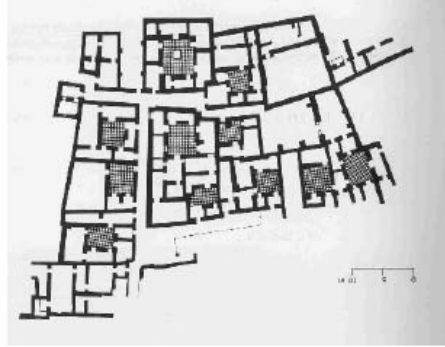

The area excavated

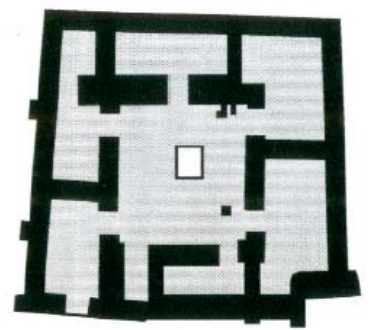

Detail of a courtyard house

Figure 3: The restitution of a courtyard house at Ur, based on excavations of the city carried out by Woolley in $1926-27$ (Source: Hisham, 2003). 

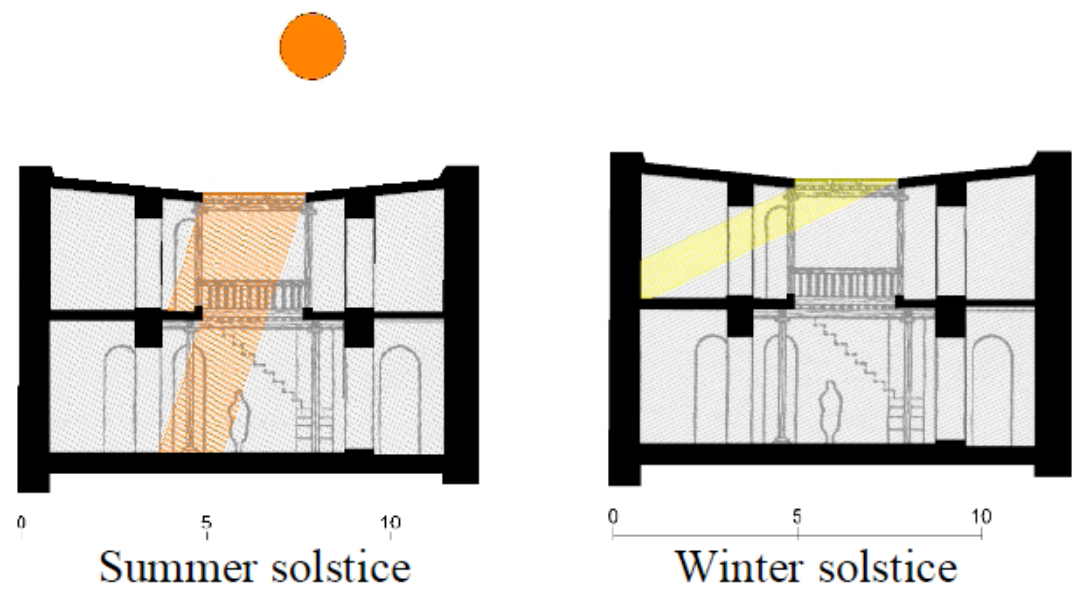

Figure 4: Simulation of the incidence of solar radiation in an excavated courtyard house from Ur corresponding to the times of the summer and winter solstices (Source: author's interpretation).

It runs from north to south, providing the perfect geographical environment for observing the solar orbit and for the sun to profoundly penetrate the consciousness of the people who inhabited this region. For some authors, this is crucial for understanding the sun-worshipping cult which was developed by early civilizations and the importance that astronomical orientations had in their architecture. As Giedion has already observed: "the Sun moves over the vastness of the desert, radiating it with extraordinary force. In the minds of the ancient inhabitants of the valley, this daily routine represented the battle between light and darkness: between the forces of good and evil. This stimulated their imagination to transfer the physical reality to the mythical and religious sphere..." [6].

Ever since the first dynasties ruled Ancient Egypt, the Sun worship formed part of their belief system and was associated with political power. The pharaohs, or "sons of the sun", were the keepers of the celestial power and $\mathrm{Ra}$, the sun god, was represented as the midday sun in all its splendour. This radiant sun was considered the most important Egyptian deity. Indeed, Pharaoh Amenhotep IV (1365-1348), who took the name of Akhenaton, even managed to establish a monotheistic cult exclusively based on sun worship.

It was on this view of the word that the ancient civilization of the pharaohs was based. Ancient Egypt's stars and constellations were mentioned in its sacred scripts and they were reproduced in the form of sun dials on the astronomical ceilings of some tombs, such as that of Senenmunt at Dendera [7].

The practical application of this cosmological knowledge was captured in a calendar based on a solar year which allowed them to anticipate the arrival of the seasons. Being able to forecast floods was vitally important as this was a civilization that depended on the seasonal rise of the River Nile to fertilize it crops and guarantee its harvests. This necessity to predict seasonal changes, combined with a high level of astronomical knowledge, explains why these solar calendars appeared.

In fact, the first Ancient Egyptian calendar was based on lunar cycles. The Ancient Egyptians realized that the star Sirius appeared alongside the sun throughout the 365 days of the year. This explains why they divided their calendar into a 365-day year. [3].

In the Ancient Egyptian civilization, the sun was not only part of religious belief, but also had a direct influence on architecture.

Astronomical alignments are relevant in the urban layout of Ancient Egyptian cities and the orientations and layouts of their most important monuments and the regulation of the sun's light determines the typological organization of their dwellings.

\section{THE PYRAMIDS: ASTRONOMICAL ALIGNMENTS AND GEOMETRIC PRECISION.}

There is no doubt that the pyramids, which are probably the world's most famous funerary monuments, follow specific astronomical alignments. It is clear that the Ancient Egyptians were able to identify the position of Polaris, the Pole Star, and to establish a precise north-south axis. This can be seen in the orientation of the pyramids of Cheops, Khafre and Menkaure, IV dynasty (2686-2494), which stand on the Giza Plateau, on the outskirts of the modern city of 

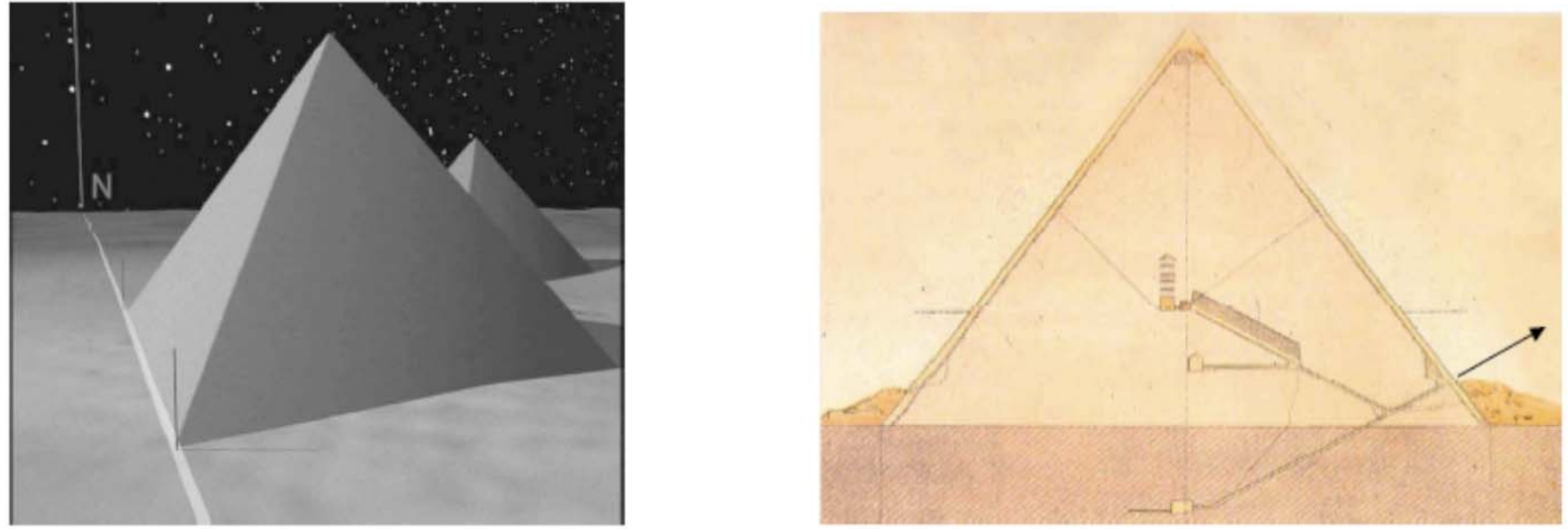

Polaris

Figure 5: Left, Alignment of the Pyramid of Khafre with the position of the stars Pheeda and Megrez in the constellation of Ursa Major (the Great Bear, also popularly known as the Plough or the Big Dipper) in the year 2545 B.C. Right, section of the Pyramid of Cheops with its access gallery pointing towards Polaris (Source: Emille Prisse).

Cairo. Solar geometry played a very important role throughout their construction process. The whole complex is oriented according to the four points of the compass and an archeoastronomical study conducted by Spence made it possible to establish the date of their construction [8]. The exact year in which the great pyramid of Cheops was constructed was 2545 BC, which coincides with the time of the stars Pheeda and Megrez crossing the meridian (Figure 5 left).

The precision of the orientation towards the four points of the compass shows great knowledge and expertise. According to Spence, it only deviates by $36^{\prime \prime}$ from the exact north-south orientation (Spence 2000). The point of access to the interior was via an entrance door on the northern side of the pyramid. This was located $16.80 \mathrm{~m}$ above ground level and provided access to the pyramid by means of a downwardsloping ramp constructed at an angle of $26^{\circ} 31^{\prime} 23^{\prime \prime}$. Spence also noted that if this ramp was extended and projected towards the sky, it pointed to the exact position of Polaris at the time of the pyramid's construction (Figure 5 right).

\section{TEMPLES}

A study of the stars was also useful for determining the exact location of Ancient Egyptian temples: they were positioned along the route from the exterior to the interior sanctuary, which was exclusively reserved for the high priest and the pharaoh and followed the sun path.

The vast majority of Ancient Egyptian temples had an astronomical alignment based on the orientations of the solstices. The alignment of a sanctuary was determined by a ritual related to the observation of the night sky and the exact position at which the star Sirius appears above the horizon (heliacal rising) with the first light of dawn; it is visible at sunrise, but soon disappears due to the brightness of daylight.

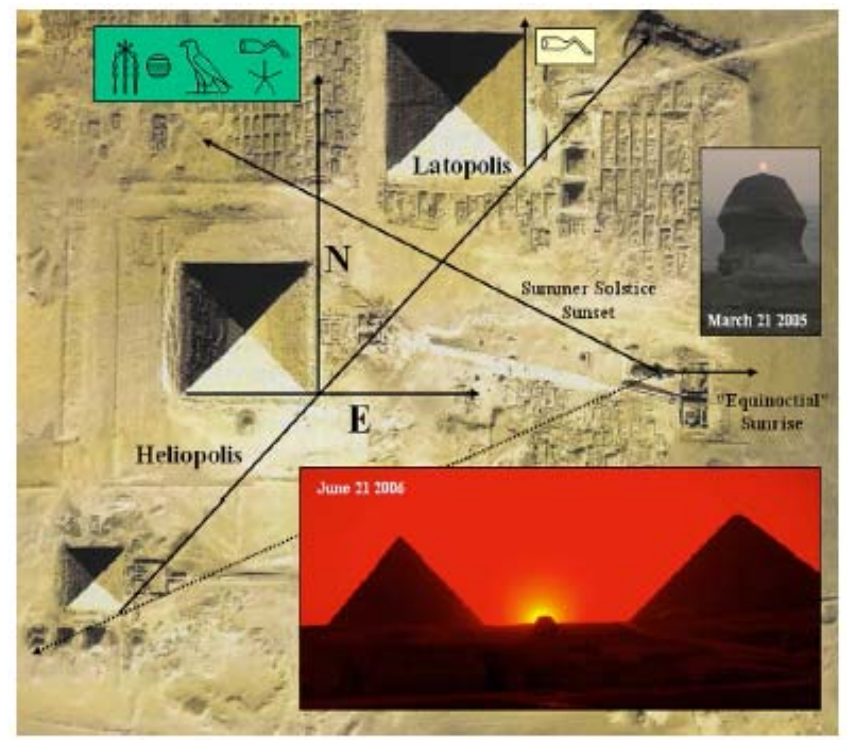

Figure 6: Schematic diagram showing the astronomical and topographic relationship between two different monuments built at Giza. It shows the northward orientation of the pyramids and the possible astronomical connection between the Sphinx and sunset at the winter solstice to the southeast of the Pyramid of Menkaure [9] (Source: Belmonte).

In line with pharaonic ritual, the Architecture of Natural Light was used to model and illuminate the inner space. In all of the great temples of Egypt, the zenith and lateral apertures have an exact geometry and are orientated with respect to the movement of the sun at different times of the year. The purpose behind this was to direct light onto a specific figure or a determined location. The precision involved in achieving this shows the existence of a profound 

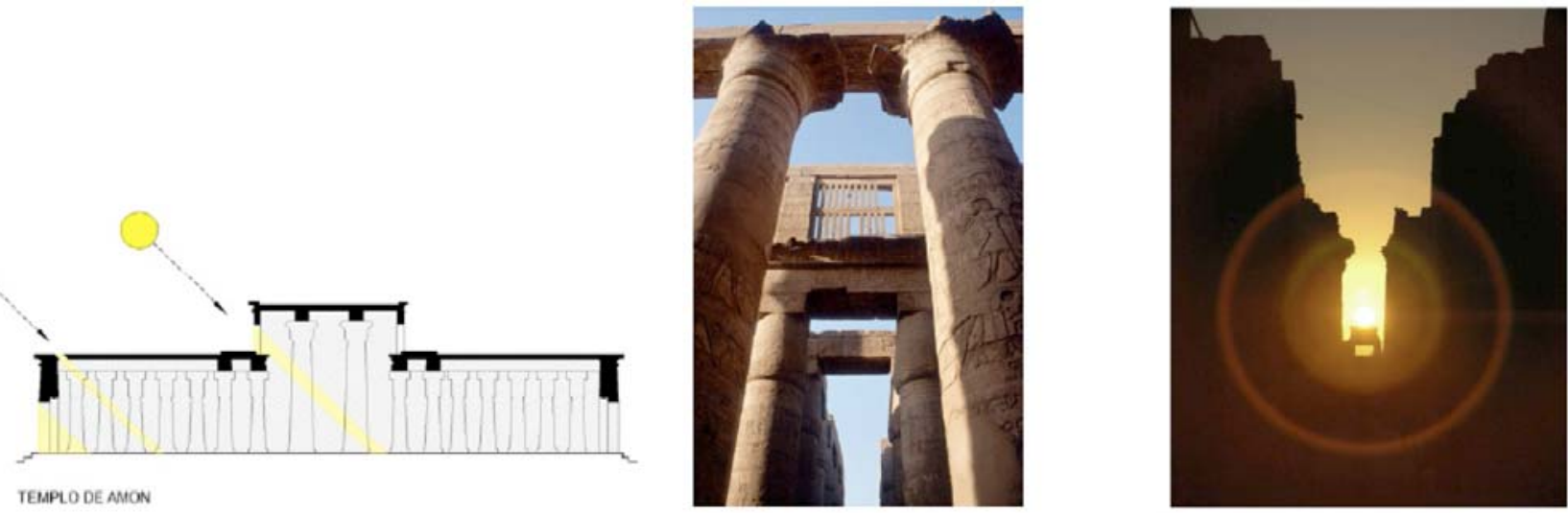

Figure 7: Left, and centre, the Temple of Amon at Karnak with detail of the zenith illumination in the hypostyle hall (source: author's interpretation). Right, sunrise at the winter solstice on the main axis of the temple of Karnak (Source: Belmonte, 2005).
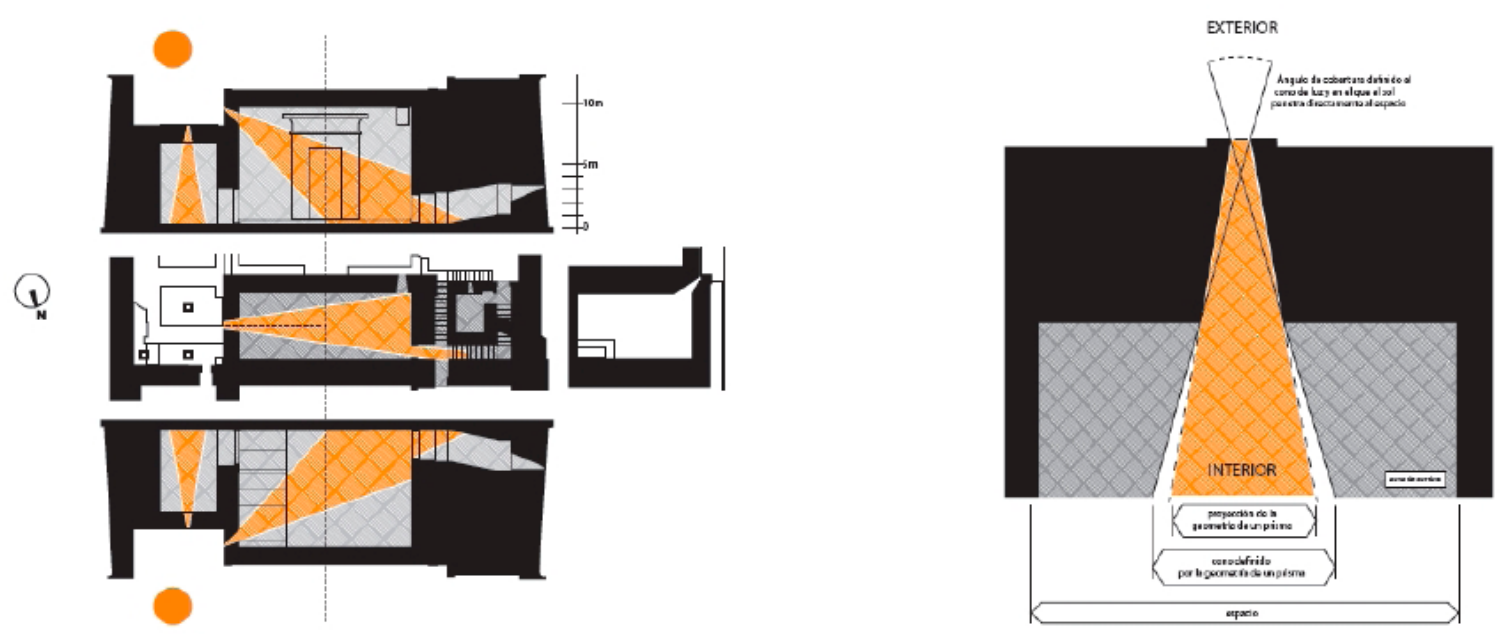

Figure 8: Openings for lateral and zenithal lighting: geometric relationships between the zenithal and lateral dimensions in the temple of Hathor at Dendera (Source: Zignani).

knowledge and a special ability for achieving special technical effects. The resulting decoration and lighting had a dramatic effect: the rooms inside the structure seemed to become lower as the intensity of the natural light progressively declined as it moved deeper into these inner spaces. By playing with the light and shadow, the user was introduced into a mysterious space with polychrome walls until they reached the deity's sanctuary where there was almost total darkness (Figure 7).

This orientation of the temples has been verified by Zignani at the temple of Hator at Dendera, a Late Egyptian temple that helped to keep sun worship and astronomy very much alive, as can be seen from the reliefs sculpted on its ceiling. In the temple of Hathor (which was found to have an orientation of $18^{\circ} 65^{\prime}$ north), the perpendicular to this axis corresponds to a particular astronomical phenomenon. At the time of its foundation, on $16^{\text {th }}$ July in the year $54 \mathrm{BC}$, it was aligned with the heliacal rising of $\operatorname{Sirius}^{3}[10]$.

As in all the other Egyptian temples, the natural lighting in the different rooms of the building served to emphasize the relationship with god that was enjoyed by the high priests and the pharaoh, which was very different from that of the normal people. In the hypostyle hall of the Temple of Amun-Re at Karnak, the space is illuminated via stone latticework located in the upper fringe of the lateral walls, just below the flat ceiling, which allows a little sunlight to enter the room, thus generating semi-darkness. Access to the room on the ceremonial path was limited to the pharaoh's family and to priests.

\footnotetext{
${ }^{3}$ The star Sirius has the peculiarity that its heliacal rising occurs at a time that almost coincides with the Nile flood (in around the third week in July).
} 


\section{RESIDENTIAL TYPOLOGIES}

The different astronomical knowledge required to allow someone to know the exact path of the Sun's elliptical orbit in different seasons of the year also had a practical application in the layout of cities and the construction of homes.

The origins of some Egyptian cities have been linked to the construction of a particular pyramid, as the artisans who worked on the pyramid and their families would have lived in colonies established for at least the time required to build it. Towards the end of the third millennium BC, the city of El Kahun [11] was formed by straight streets which intersected at right angles. The courtyard houses had four rooms that were protected from the sun by small exterior openings which provided only limited natural lighting due to the need to provide maximum protection from the intense sunlight. This restriction of natural lighting created rather gloomy spaces that opened onto interior courtyards which were probably covered by light structures constructed from natural elements whose central areas would have provided shade and vegetation (Figure 9).
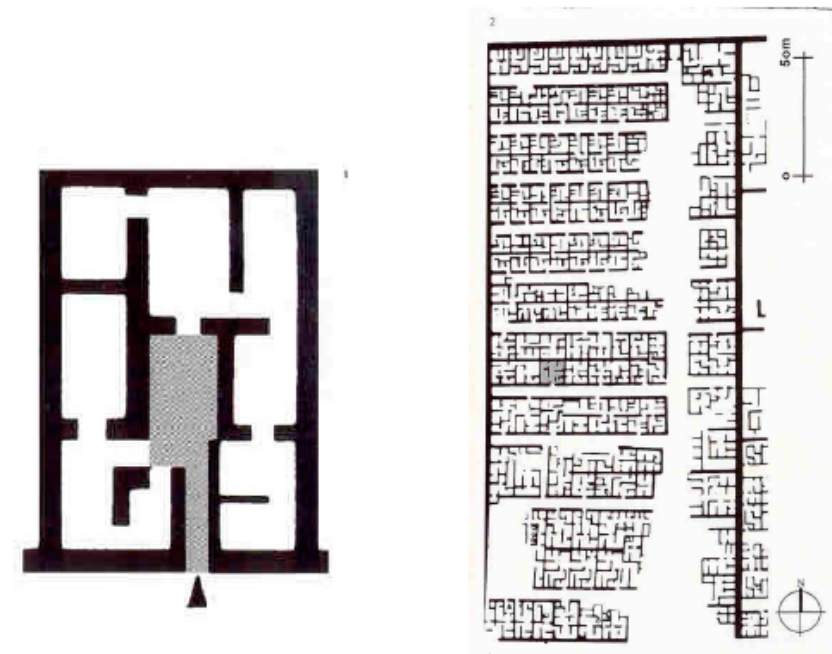

Figure 9: Kahun (Source: Flinders Petrie).

Homes located in the suburbs of cities housed a cross-section of society of differing levels of wealth, in which the pharaoh occupied the highest position in the social hierarchy. These houses mostly fit the typological of courtyard housing. The house reproduced below in bas-relief, which dates from 1300 BC (Figure 9 left), contains all of the compositional and typological elements of Egyptian vernacular architecture: the house is organized around a patio containing dense vegetation, which is represented by palm trees in the image, while the functional programme is developed on two stories. The wind catchers used to bring external fresh air into the houses were built into the flat ceilings and the windows were covered by latticework to limit the impact of the intense solar radiation. 3,000 years later, the same pattern is still valid for tempering the desert climate.

\section{DISCUSSION AND CONCLUSIONS}

This article seeks to examine the origins and influences of Solar Architecture by analysing the constructions and monuments built by the first urban civilisations. The novelty of this research lies in the relationship that it establishes between Cosmology and solar design in the Ancient World. In doing this, we refer to data obtained from other earlier works which are considered basic for reviewing the "state of the art"; in other words, this interpretation has been based on all the knowledge currently available.

Here, we have tried not to fall into the trap of engaging in inconsistent speculation. This is something which has happened on many occasions when other authors have either failed to examine this subject with the necessary epistemological tools or the required degree of knowledge and/or objectivity. These are failings that have often given rise to almost esoteric interpretations.

The starting point for this research is already known and has been explained in detail in the fields of anthropology and archaeology. Since the earliest human societies, all of these cultures have sought some form of explanation to help them understand the vastness and power of the cosmos and its relationship with the natural world and everything that can be found within it. The inability to unravel this mystery no doubt lies at the base of, or helps to explain, the appearance of the first religious beliefs: the idea of a superior being which manifested itself through sunlight and led to sun worship.

The need to find responses to this concern produced an astronomical culture, based on the observation of the stars and the analysis of their respective positions and movements across the heavenly vault, which was present in all of the most important civilisations of the Ancient World, and particularly in those analysed in the present article. The abstract interpretation of the movement of the sun, between sunrise and sunset, at different periods of the year, served as the basis for the establishing the earliest mathematical knowledge. This was particularly 

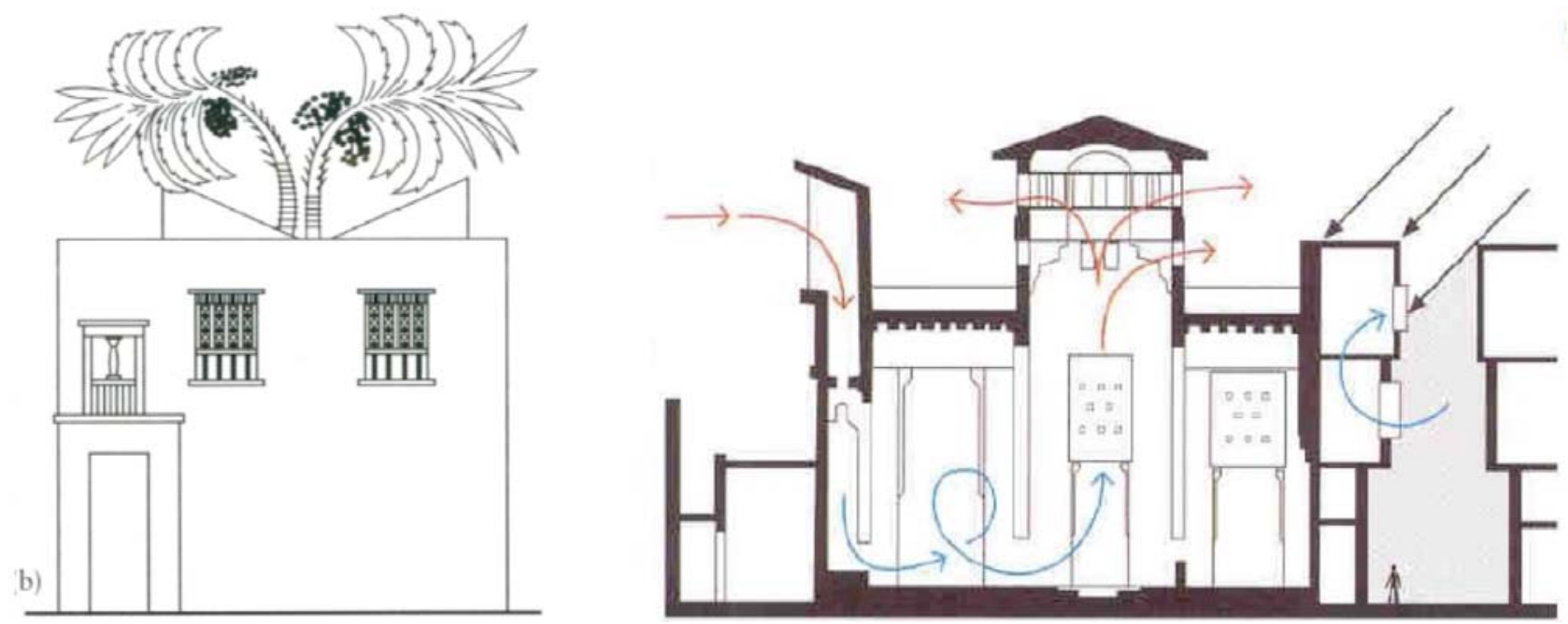

Figure 10: Left, house in Ancient Egypt, according to a bas-relief found in the tomb of the pharaoh Neb-Amun (1300 B.C.); it features a patio with palm trees and wind catchers (Source: M. Hisham). Right a traditional house in the historic centre of Cairo).

evident in the cultures of Mesopotamia and Egypt, where this "corpus" of abstract knowledge had practical consequences:

First, it is important to highlight its influence in the construction of great civil, religious and funerary monuments. An analysis of perfectly documented archaeological remains studied by authors from the discipline known as Archaeoastronomy demonstrates the influence of astronomical alignments in the composition of some of the main constructions erected by the cultures of the Ancient World [12]. This is apparent during different periods and at different places on the planet, with particular relevance in some Neolithic cultures, such as those of Mesopotamia and Egypt.

Secondly, it relates to its role in shaping domestic architecture. This vernacular architecture arose from the need to adapt to local climates and natural settings at a time when there was a shortage of primary energy sources. At that time, passive solar design was used as a more direct tool with which to make buildings more thermally comfortable.

It is therefore possible to establish a direct relationship between cosmology, sun worship, the origins of early mathematics and its practical application in the architecture of buildings constructed with specific solar orientations. It is possible to deduce, and this would be one of the conclusions drawn from this revision article, the existence of a guiding thread, which some other authors have referred to as a "golden thread" [13] which binds together a history of Architecture and Solar Technology. This did not, however, - and this is the novelty in this account - begin in the Greek World, the hearth of Western Civilization, 2,500 years ago, as these other authors suggest. Instead, it is necessary to go much further back in time, to at least the year $1800 \mathrm{BC}$, the approximate time of the construction of Stonehenge and of the first cities built by the Sumerian civilisation.

\section{REFERENCES}

[1] Martínez Flores J. Stonehenge, donde los astros y dólmenes danzan, info-astro, astronomía digital 꾸, enero. Agrupación astronómica de Gran canaria 1999; p. 45.

[2] Belmonte JA. De la Arqueoastronomía a la Astronomia Astronomía cultural, Boletín de la SEA no 15, invierno 20052006; p. 32.

[3] Hemenway P. Le code secrete. La formule mysterieuse qui regit les arts la nature et les sciences. Evergreen, Kóln, 2008; p. 33

[4] Edwards B, Sibley M, Hakmi M, Land P. Courtyard Housing, past, present and future, OXON, Taylor \& Francis, 2006; p. 192.

[5] Hisham M. Traditional Islamic Principles of Built Environment, Routletge Courzon, New York 2003; p. 64.

[6] Giedion S. El presente eterno; los comienzos de la Arquitectura, ALIANZA FORMA 1981; pp. 24 and 111.

[7] Belmonte JA, Zedda MP. Light and shadow on the pyramids. SEAC Congress. Light and shadow in cultural astronomy, proceedings 2005.

[8] Spence K. Ancient Egyptian chronology and the astronomic orientations of pyramids. Nature 2000; 408: 320-324. http://dx.doi.org/10.1038/35042510

[9] Belmonte JA, Shaltout M. keeping Ma'at: An astronomical approach to the orientation of the temples in ancient Egypt. Advances in Space Research 46: pp. 532-539, Sciencie Direct, Elsevier. http://dx.doi.org/10.1016/j.asr.2009.03.033

[10] Zignani P. Enseignement d'un temple egyptien, Presses polytechniques et universitaires romandes, Lausanne 2008; p. 46. 
[11] Flinders Petrie WM. A History of Egypt, from the Earliest Kings to the XVIth Dynasty. 6 volumes. London 1894.

[12] Belmonte JA, Zedda MP. Light and shadows on the pyramids, proceedings of the SEAC 2005.
[13] Butti K, Perlin J. Golden Thread, 2500 years of solar architecture and technology, Marion Bayars Publishers Itd. London 1980; p. 2-18.

Received on 05-07-2014

Accepted on 20-08-2014

Published on 20-11-2014

(C) 2014 Guardiola et al.; Avanti Publishers.

This is an open access article licensed under the terms of the Creative Commons Attribution Non-Commercial License (http://creativecommons.org/licenses/by-nc/3.0/) which permits unrestricted, non-commercial use, distribution and reproduction in any medium, provided the work is properly cited. 